\title{
What Makes an Excellent Surgeon?
}

\section{Barry Jackson ${ }^{1}$}

Published online: 11 March 2019

(C) Springer Science+Business Media, LLC, part of Springer Nature 2019
I am acutely conscious that I have been given something of a poisoned chalice, for I stand the risk of being seen as holier than thou. I do hope the audience will not think me so. You have asked me to address the question 'what makes an excellent surgeon?' not, 'what makes a competent surgeon?' The two are not synonymous. There are many competent surgeons, but many fewer would rank as truly excellent. Some may disagree with me about that but even so, in the next $15 \mathrm{~min}$, I am going to outline the qualities that I believe are necessary.

Had I been asked to speak on this subject in the early nineteenth century, it would have been an easy task. One word would have been all that was needed - speed. The truly great surgeons of that time were those who could amputate a leg or a female breast with extreme rapidity, Robert Liston of University College Hospital perhaps being the exemplarleg off in 30 seconds! Shock was thereby minimised leading to survival, provided blood loss was controlled - the assistant being largely responsible for that! The introduction of anaesthesia negated the need for speed but, even so, many surgeons were still judged by their speed of operating. Thankfully, those times are now long past. Speed is no longer a factor.

By the turn of the nineteenth century, antisepsis followed by asepsis had been introduced and it was boldness that characterised the really great surgeons - those who were willing to attempt procedures never before contemplated and to advance what was technically possible: Think Billroth in the abdomen and, a little later, Harvey Cushing in neurosurgery.

Barry Jackson is a past president of the Royal College of Surgeons of England (1998-2001). He was also the Serjeant Surgeon to the Queen from 1991-2001.

Presented as a keynote lecture at the 1st International Bariatric Club Oxford World Congress at Christ Church, University of Oxford, on March 26th, 2018, with the kind permission of the speaker, Sir Barry Jackson, and Mr. Haris Khwaja, Director of the 1st IBC Oxford World Congress.

Barry Jackson

barryjck7@aol.com

1 London, United Kingdom
Of course, they did not always succeed and disasters often resulted but nevertheless, they were the surgeons of the day and many of their names live on.

But over the course of the twentieth century, technical achievement in all branches of surgery became established and the perception of the excellent surgeon changed. By the 1950s, the archetypal great surgeon, certainly in the eyes of the public, was Sir Lancelot Spratt of Doctor in the House fame: supremely confident, flamboyant, dogmatic... and rich (private practice fees before the NHS were high)! A chauffeur-driven Rolls Royce was an essential. Even quite recently, it was said that success in the private sector demanded the three As - availability, affability and ability, in that order. And it remains true that many GPs judge surgeons by different criteria than do surgeons themselves.

However, we are now in the twenty-first century and the qualities needed for excellence in surgery are vastly different. Perhaps, an excellent surgeon can be defined as the surgeon that other surgeons and their families consult when surgical advice or operation is needed. But if so, what is it that distinguishes that particular surgeon from others? Many qualities are required - some essential, others merely desirable. Let me disagree at once with the Professor of surgery who last year in the Financial Times argued quite seriously that to be a good surgeon 'you have to have the characteristics of a psychopath'. He claimed that, when a young man, a head injury he sustained while playing rugby transformed his personality making him perfect for the job!

It is of course true that many studies have shown that the personality of surgeons markedly differs from the personality of those practising some other branches of medicine, for example dermatology or psychiatry, and that some of these personality traits often veer towards assertiveness, even aggression. Most surgeons, certainly those of my generation, have experienced surgeons who not infrequently showed appalling behaviour in the operating room especially when stressful situations arose. But I suggest that, however technically competent they may have been, those surgeons were not excellent surgeons. Unacceptable behaviour in the operating theatre or outside - for example, bullying of trainees on ward rounds does not fit with the concept of surgical excellence no matter 
what other qualities the individual may possess; technically skilled perhaps, but surgically excellent no.

I also disagree with any belief that those who reach high office, such as presidents of Colleges or similar institutions, are necessarily excellent surgeons. I can think immediately of one former president of a royal college in my lifetime, he shall be nameless even though long deceased, who was widely reputed as being one of the worst surgeons in London! My scepticism also applies to well-known names through authorship of successful textbooks, again no identification, but at least one extremely well-known surgical author was known to be extraordinarily ham fisted in the operating room. But of course, very good technical skill, that is to say manual dexterity and always being in the correct anatomical plane, is one of the essentials. I do not say superlative technical skill (although this is a bonus) for we all know that in many operations that is not an essential, although, for some operations, it certainly is, a good example being micro-vascular surgery. Here, the better the quality of suturing, the better the result of the operation. But more than very good operative technique is required. First-class judgement is equally important; some would argue perhaps even more important: judgement not only in theatre but also in the outpatient clinic and during postoperative care. You all know the aphorism-a good surgeon is one who knows how to operate. A better surgeon is one who knows when to operate but the best surgeon is one who knows when not to operate. There is much truth in this! During operations, unexpected findings are sometimes encountered; anatomy may be distorted; and normal anatomical planes may be obliterated with fibrosis, tumour or other pathology. Decisions then have to be taken - perhaps to abandon one's normal routine and adopt a new approach, maybe to change the procedure or even abandon the operation completely and live to fight another day. It is in making the right call in such situations that master surgeons demonstrate their art.

More than first-class technical skill and excellent judgement is sometimes required when performing an operation. Even the best surgeons can have operations go unexpectedly wrong; an inflamed friable organ may unexpectedly rupture even with the gentlest handling, venous bleeding may suddenly be encountered from an aberrant blood vessel and access may be difficult - suddenly, there is the potential for disaster. Calmness of the mind and bearing is then required: not rising panic, not blaming your assistant, not shouting at the scrub nurse. It is something that the great physician-philosopher, Sir William Osler, called equanimity. The ability to coolly assess a difficult situation, think how best to correct it, and then proceed. Such events may occasionally require humility and moral courage, by the need to call for further skilled assistance rather than pressing on with perhaps inadequate or inexperienced assistance. Massive bleeding is an example. However senior, however experienced, the great surgeon will feel no loss of face in asking for help from a colleague.
Rightly, there is now great emphasis on the importance of team working. When I started my career, team working in the operating room was the norm. A consultant surgeon had the same scrub nurse and the same anaesthetist and an assistant who had been attached to the firm for several months, maybe longer. This concept of a regular group working as a team changed dramatically as my career progressed with rostering being introduced as a result of restricted hours of work. The surgeon, scrub nurse, anaesthetist and assistant who have never worked together previously are not in a situation that leads to easy harmony. Recognising this, part of the WHO surgical safety checklist, now routine in the UK, ensures that everyone in the operating room is properly introduced and that everybody knows what operation is to be performed and of any potential problems.

An excellent surgeon should get first-class outcomeswhich of course is what the patient and their relatives want. But beware - outcome data can be seriously misinterpreted without allowing for case mix. A mediocre surgeon may have excellent outcomes because they operate only on the easier cases while a first-class surgeon who operates on the most difficult and demanding cases may have seemingly less good outcome data. This is the risk of unadjusted league tables. Sometimes, even when case mix is allowed for, analysis of the results for a particular procedure shows less than ideal outcomes. It is then that insight is required as to why this might be. Critical analysis of one's personal outcomes should be second nature throughout a surgeon's career, and if any deficiency is shown, steps must be taken to address it. On occasion, this may require retraining in a particularly complicated procedure.

The qualities of an excellent surgeon go on.

Knowledge is perhaps self-evident, but the need to be able to adapt to the new and learn continuously throughout one's career is essential. It is important to be willing to change one's practice when demonstrably better techniques emerge, perhaps, even to stop performing certain operations altogether when better methods of treatment have become established. For example, some surgeons in the nineties and noughties were very slow to accept that minimal invasive techniques had not only arrived but were here to stay. Indeed, I hear rumour that, even today, there are still a minority of senior surgeons in the UK who are performing open cholecystectomy as a routine. That is bad practice for, if they have not learned minimal invasive techniques, now standard for cholecystectomy, or have found that they do not have the necessary skills required to practise them; then, they should refer the patient to a colleague who has. I was brought up on the motto big surgeon — big cut! Looking back, how incredibly archaic that now sounds! But of course, open operations are often still required and then adequate access to safely perform the procedure is always an essential. A large incision may sometimes be necessary. 
Communication skills are vitally important. The ability to communicate with patients and their relatives in a quietly confident way, at all times being honest and understandable is part of the hallmark of a master surgeon. Arrogance or seeming superiority should be abhorred. A good technician with a poor bedside manner does not equate to true excellence. Communication with one's colleagues is also important and the acceptance of differing points of view. Communication and team working are necessary components of good leadership, a quality which is also part of the persona of the master surgeon, who is also likely to be a good teacher-avoiding humiliation of a student or trainee in front of others - something which still occurs all too frequently and of course does not engender good learning. The ability to critically appraise and analyse scientific literature is necessary and this ability is furthered by having had firsthand experience of research, although I do not believe outstanding excellence in personal research is an essential component of surgical excellence. But it goes without saying that a high ethical standard is essential, not only in any research that may be pursued but also in one's conduct generally.

So these are some of the qualities that I believe are required to answer the question posed. I end with the Golden Rule, something that is innate in the best surgeons - do unto others as you would have done unto yourself. By following this rule at all times, in the outpatient clinic, in the operating room and during postoperative care, all doctors, whatever their specialty, will be on the path to excellence - it is a rule that I always strived to practise during my own career. But was I an excellent surgeon rather than merely competent? That I honestly do not know-it is always for others to judge, not the surgeon themselves. And there is no one here you can ask; I confess to being mightily relieved!

Thank you for listening.

\section{SIR BARRY JACKSON MS FRCS FRCS (GLAS) FRCP}

Sir Barry Jackson was the Serjeant Surgeon to the Queen from 1991 to 2001 and President of The Royal College of Surgeons of England from 1998 to 2001. He was also President of the Royal Society of Medicine (2002-04) and the Association of Surgeons of Great Britain and Ireland. He was an elected member of the General Medical Council and civilian consultant surgeon to the Army. He has been awarded numerous professional honors including a knighthood for services to training and education in surgery. He was a member of the consultant staff of St Thomas' Hospital, London for thirty years specializing in surgery of the gastrointestinal tract. He is currently a Trustee of several health-related charities and is actively involved in the library and museum services of the Royal College of Surgeons. He has a longstanding interest in the history of medicine.

Publisher's Note Springer Nature remains neutral with regard to jurisdictional claims in published maps and institutional affiliations.

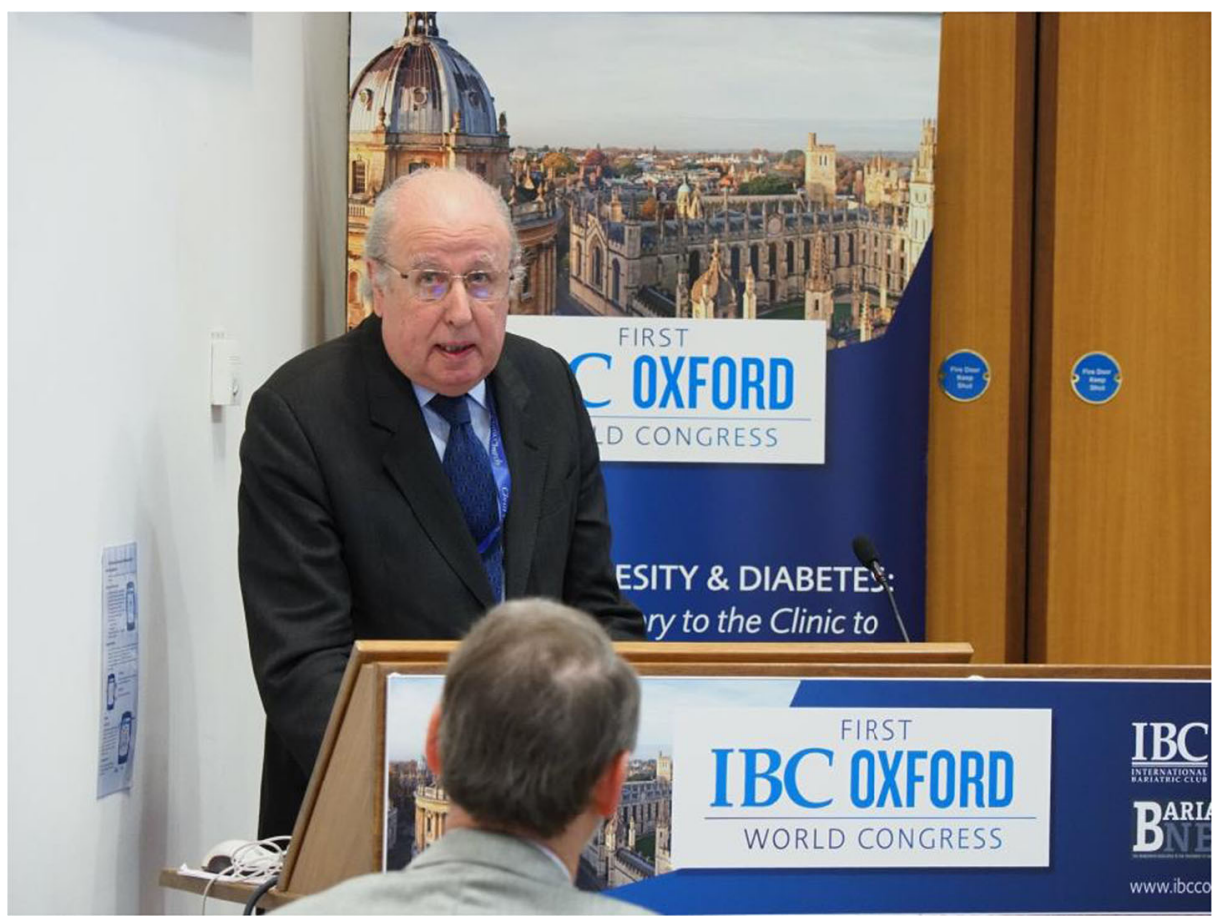

